\title{
Instrumentation of Infiltrometers with Arduino to Determine Soil Water Infiltration Rate
}

\author{
Afranio Almir Righes, Felipe Henrique Moraes, Galileo Adeli Buriol \\ Environmental and Sanitary Engineering Program at UFN, Franciscan University, Santa Maria, Brazil \\ Email: afranio.righes@gmail.com, felipe.moraes@ufn.edu.br, galileoburiol@yahoo.com.br
}

How to cite this paper: Righes, A.A. Moraes, F.H. and Buriol, G.A. (2020) Instrumentation of Infiltrometers with $\mathrm{Ar}$ duino to Determine Soil Water Infiltration Rate. Agricultural Sciences, 11, 1109-1115. https://doi.org/10.4236/as.2020.1111072

Received: September 23, 2020

Accepted: November 22, 2020

Published: November 25, 2020

Copyright $\odot 2020$ by author(s) and Scientific Research Publishing Inc. This work is licensed under the Creative Commons Attribution International License (CC BY 4.0).

http://creativecommons.org/licenses/by/4.0/

(c) (i) Open Access

\begin{abstract}
The intense mobilization of the soil inappropriately causes a reduction in the percentage of macropores and in the rate of soil water infiltration with reduction of crop yield. Due to the difficulty of using the Muntz concentric ring method, researchers have used mathematical models to estimate infiltration based on soil physical parameters such as, soil texture that does not reflect physical reality in relation to infiltration rate, leading to errors. To automate the use of the infiltrometer ring method, there are no hydrometers that record small flows in non-pressurized hydraulic systems, making it difficult to automate the method for field determination. For this purpose, six Muntz double rings were instrumented with an electromechanical system coupled to the "Tipin Buked" (weighbridge) with the ability to record flows from 8 $\mathrm{cm}^{3} \cdot$ minute $^{-1}$ on a memory card. The results indicate that the models of the regression equations describe $93 \%$ to $99 \%$ of the real values, showing the accuracy of the equipment. This work aimed to modify the Muntz method to reduce field work and automate the determination of water infiltration rate in the soil.
\end{abstract}

\section{Keywords}

Tipin Buked, Arduino, Automation Method of Double Rings

\section{Introduction}

The infiltration of water in the soil is the component of the hydrological cycle most responsible for the processes of erosion, flooding, aquifer recharge and water storage in the soil that directly interfere in the availability of water for crop productivity. Water is a limiting factor in agricultural production. According to Sotério; Petrollo \& Andriotti [1], the average annual precipitation in the State of Rio Grande do Sul is $1721 \mathrm{~mm}$. In these conditions of rainfall and environmental 
susceptibility, proper soil management is essential. The recurrent problems of floods and droughts, in the state of Rio Grande do Sul, are directly linked to the intensity and duration of rainfall and the capacity of soils to infiltrate and store rainfall water. The intensive use of agricultural soil, reduced macroporosity and consequently the basic rate of water infiltration, as well as the availability of water for crops. According to Denardin J. E. Kochhann, R. A. \& Righes, A. A. [2] low values of infiltration dramatically reduce the water storage in the soil and aquifer recharge, increasing runoff and flooding.

The droughts that occurred at Rio Grande do Sul state in 2004/2005, 2008/2009 and 2012/2013 drastically reduced the production of agricultural crops with negative impacts on the State's accumulated GDP in the order of $-3.1 \%,-5.2 \%$ and $-4.1 \%$, respectively [3]. Monitoring the rate of water infiltration is essential to select the best soil and management techniques to be used to increase water infiltration.

Among the methods available to determine the rate of water infiltration into the soil, the concentric ring method (Muntz ring) is the most used method for simplicity. However, they demand many repetitions, with a lot of work and need trained field personnel to obtain data [4].

The traditional method to determining the infiltration rate at field conditions using the double rings of Muntz, it is known that the higher is the rate of water infiltration into the soil, the more frequent are the readings of the infiltrated. Water volume in the graduate reservoir should be performed. Thus, the initial readings should be performed in shorter time intervals, requiring frequent notes on spreadsheets from the researcher. With these values, the water infiltration curves will be generated, which should be the most representative of the reality, for not to be induce in errors in the determination of this parameter.

Considering also, the lack of hydrometers on the market that can register low flow rates as $8 \mathrm{~cm}^{3} \cdot \mathrm{min}^{-1}$ without hydraulic head this work was developed. The electromechanical pulse system coupled to the tipin buked provides in loco, with precision, continuous and automatic monitoring of the infiltrated water volume as a function of time, simultaneously in the six sets of infiltrometers, recording the data in a free electronic prototyping platform arduino. This electronic system was designed in Italy on a platform with its own language based on wiring, a programming structure that allows the micro controller to act on other devices connected to it that inform the time and number of pulses Souza [5].

The Rio Grande do Sul state is located between, $27^{\circ}$ and $35^{\circ}$ south latitude, which according to Hudson [6] is in the region between $40^{\circ}$ North latitude and $40^{\circ}$ South latitude from the Equator. The region is highly susceptible to environmental degradation when the natural vegetation cover is removed.

It is very important to obtain reliable hydrological data, in a practical and efficient way, of the basic soil water infiltration rate at different soils to give a support to define mitigation practices of adequate management in degraded and intensive cultivation areas. 
In the process to determining the soil water infiltration using the traditional method of Doble rings, the water flow in sandy soils or in forest areas is very intense and there are usually errors in the reading of the infiltrated water volume, as well as the need to replace the water volume in the graduated container that uses $Y=$ the chicken water drinker principle. Under these conditions, it is practically impossible to work simultaneously with more than one infiltrometer per person. This has led researchers to use few repetitions that, due to the spatial variability of the soil, induce errors in the determinations of this important and integrative parameter of the physical conditions of the soil. The work presented here is to modify the Muntz rings method to automate the determination the rate of water infiltration in the soil. The theme is unprecedented and innovative, allowing to perform six repetitions simultaneously with just one operator.

\section{Material and Methods}

The instrumented equipment are six Muntz double rings, installed concentrically, with 25 and $50 \mathrm{~cm}$ in diameter, both $30 \mathrm{~cm}$ high with a constant water depth, automatically maintained by means of float valves in both the inner and outer ring. The objective is to determine in the field the volume of water applied by gravity to the inner ring. Figure 1 shows the distribution scheme of the infiltrometers and other components of the system.

For this purpose, the electromechanical system coupled to the tipin buked (weighbridge) was used, with the capacity to record flow rates of $8 \mathrm{~cm}^{3} \cdot$ minute $^{-1}$. For data collection, the free programming inarduino system was used.

The programming was carried out in arduino based on a C++ system, which collects data from the sensors. Sphere sensors were used that are attracted by a permanent magnet in the movement of the tipin buked. When the circuit is closed, it reduces the signal from the digital port from 5 volts to 0 volts and is converted to digital signals, which are pulses of 0 and 1 (Figure 2).

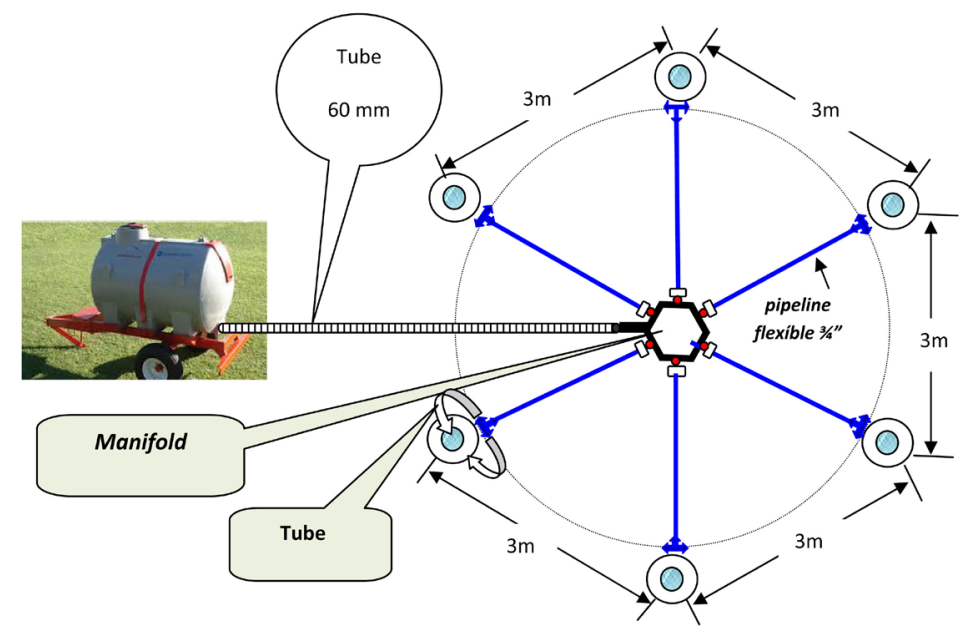

Figure 1. Field installation scheme of the water distribution system for the infiltrometer rings. 


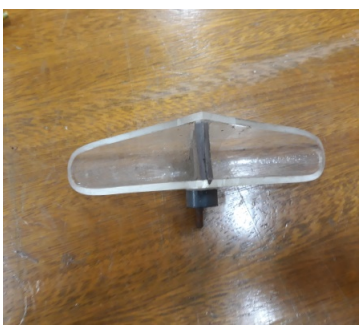

(a)

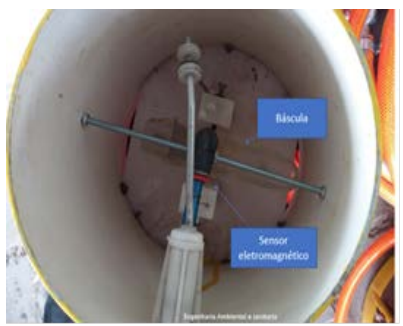

(b)

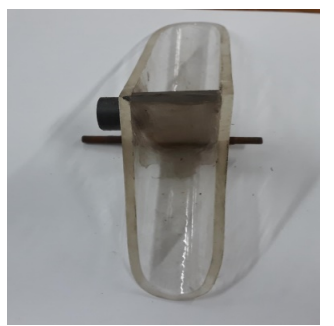

(c)

Figure 2. Tipin buked system (weighbridge) pulse generator. (a) Acrylic weighbridge with pulse sensor; (b) View of the float valve; (c) Tipin buked with magnetic sensor.

The flow determination equipment coupled to the internal ring of the infiltrometer was built in acrylic and tecnil having its electronic sensors connected to the arduino (datalogger). The power to keep the sensor system and the datalogger running is provided by the 12 Volt battery (DC). The concentric rings, in strumented electromechanical, were calibrated in the laboratory using 5 repetitions for each of the five simulated vessels. The data collected were the pulses and the respective volume of water, obtained in the interval of 1 minute. Based on these data, a regression curve was generated for each infiltrometer.

The electronic circuit of the system reduces the voltage and limits the power of the system with resistors of $5 \mathrm{k}$ and $10 \mathrm{k}$ (Figure 3), thus avoiding the equipment shutdown. Without the power limiting resistor when the voltage reaches zero volts, the equipment would be switched off. Eighteen resistors were used, 3 in each signal input, together with an LED indicating the operation of the system. The power supply is by a sealed lead acid battery of 12 volts and 7 amps, powered by (solar plate) connected directly to the equipment. It should be noted that according to the datasheet the arduino works with a voltage of 9 to 15 volts, however, it is unstable when connected directly to the 12 volt battery. Thus, to stabilize the voltage, a regulator was used that lowers the voltage from 12 to 9 volts. The entire assembly of the sensors was carried out in the Laboratory of Environmental and Sanitary Engineering at the Franciscan University (UFN).

The Arduino system was fed with the code that, by converting the analog signal to digital, with the number of pulses and the volume of water measured in the time interval. This allowed to determine the infiltration rate for each infiltrometer. In order to access the time, a "shield 1307" was attached, next to the processor to feeding the time and date with the advantage of not requiring adjustments since it already has its own source.

For the code operation, the declaration of the variables was first performed, as well as, the call of the library in order, later, the animation and explanation of the equipment and the date and time adjustment, if necessary, the card notice connected with continuation or the pause and watering of the card showing the warning "card not inserted", if everything is correct, the time and the number of pulses will appear on the device's display, showing that the system is saving the data correctly. 


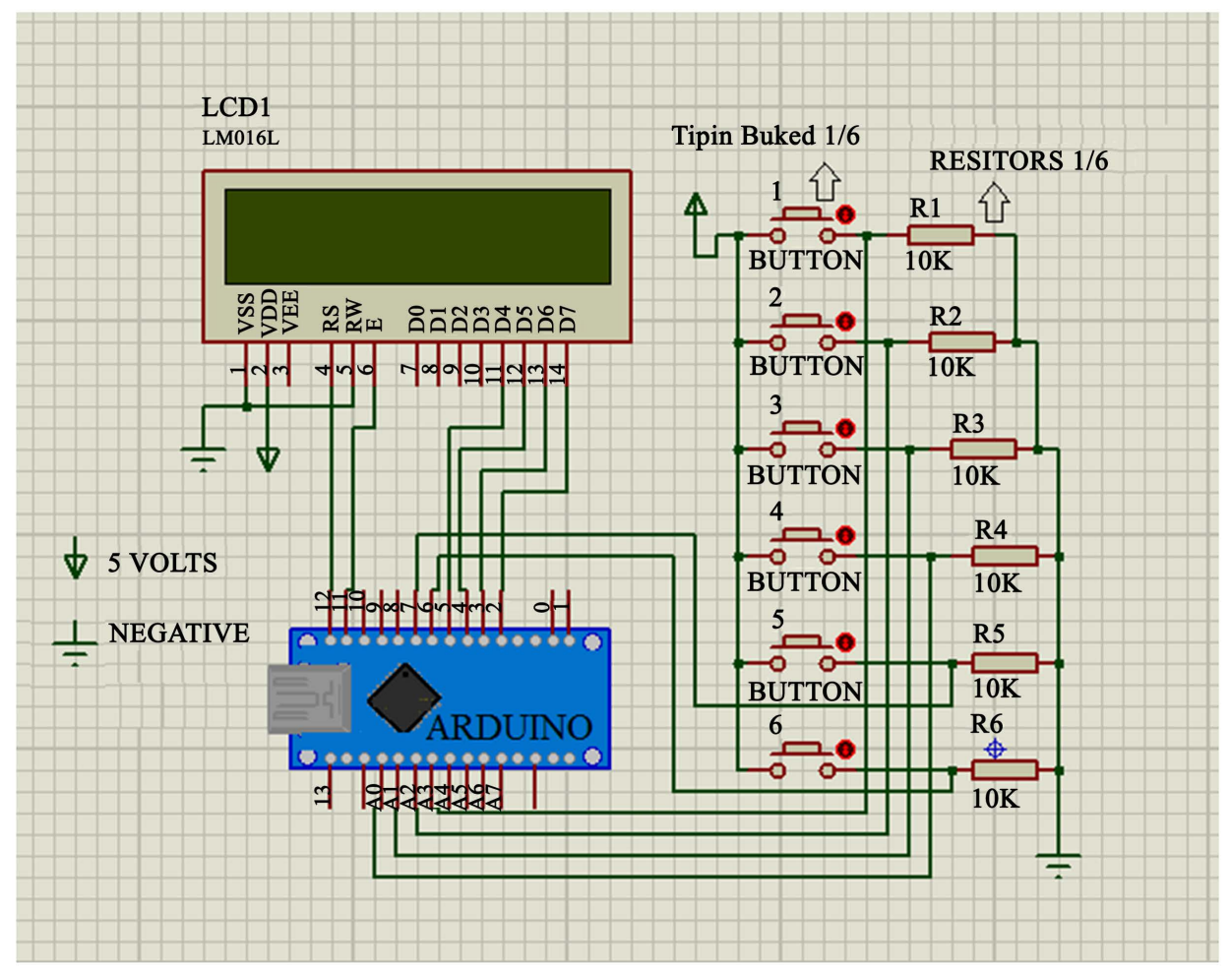

Figure 3. Electrical diagram of the equipment.

\section{Results and Discussion}

Several simulations were performed before obtaining the regression equation, the first simulations showed mechanical and software failures that were remedied. The calibration of the equipment was performed after remedy these errors. The calibration was carried out in the soil laboratory at the Environmental and Sanitary Engineering course at UFN. To determine the volume of water in the time interval of one minute, the mass of water obtained was determined. For this, a scale with a precision of $0.01 \mathrm{~g}(1 \mathrm{~kg}=1 \mathrm{~L})$ was used. Five flows were simulated with five repetitions per flow, generating 25 points, and with the aid of the Excel software, the regression equation was obtained for each infiltrometer (Table 1, and Figure 4).

The system was field-tested on soil at the São Pedro mapping unit (Arenic Red Distrophic) grown with vines of the burgundy variety at Santa Maria RS, using the Doble ring infiltrometer method [7].

Figure 5 shows the values of the water infiltration rate in the soil.

Table 2 shows the result of the basic rate of water infiltration in the soil after 7 hours of simulation.

The basic rate of infiltration stabilized after 7 hours of determination. The highest infiltration values occurred in the interval from 0 to 15 minutes due to the simultaneous presence of the matrix soil water potential and gravitational potential. When stabilization reached, the water flow is due only to the gravitational potential. 

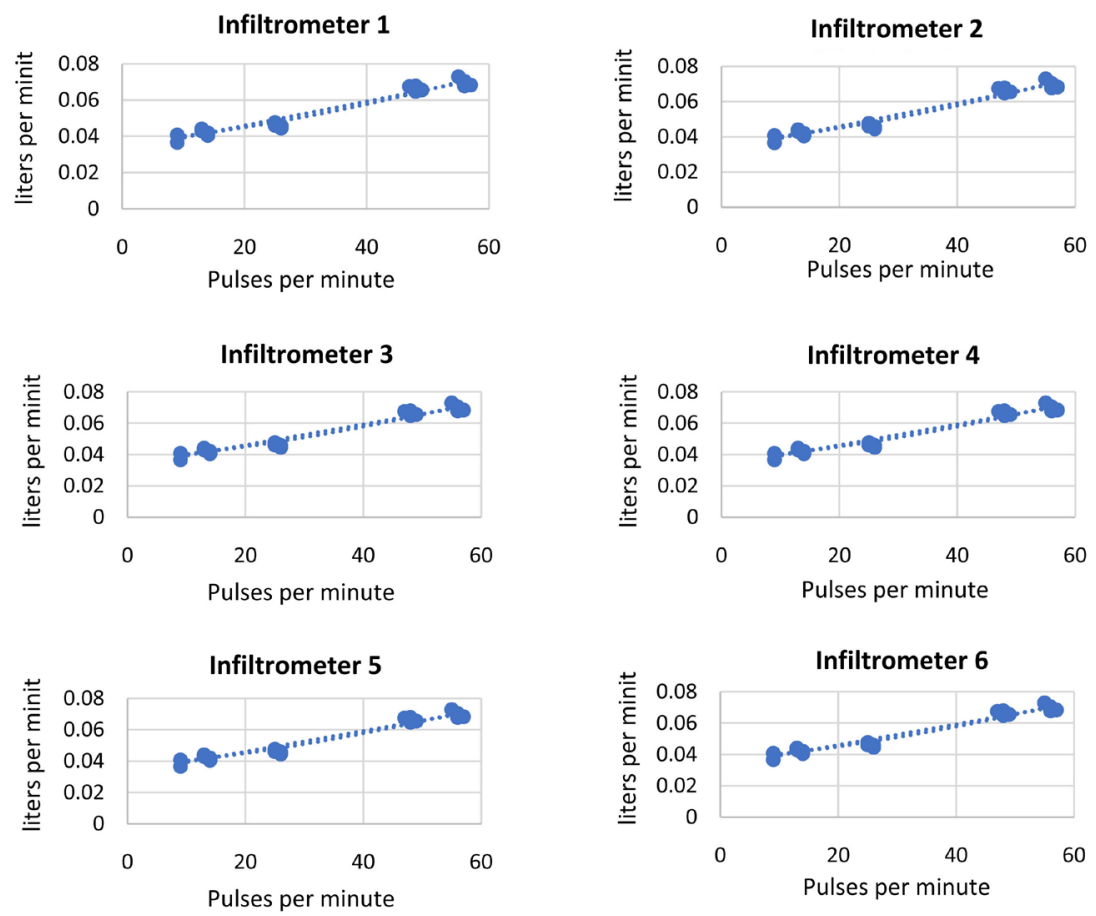

Figure 4. Regression equations the number of pulses with the water volume determined by the six instrumented infiltrometers.

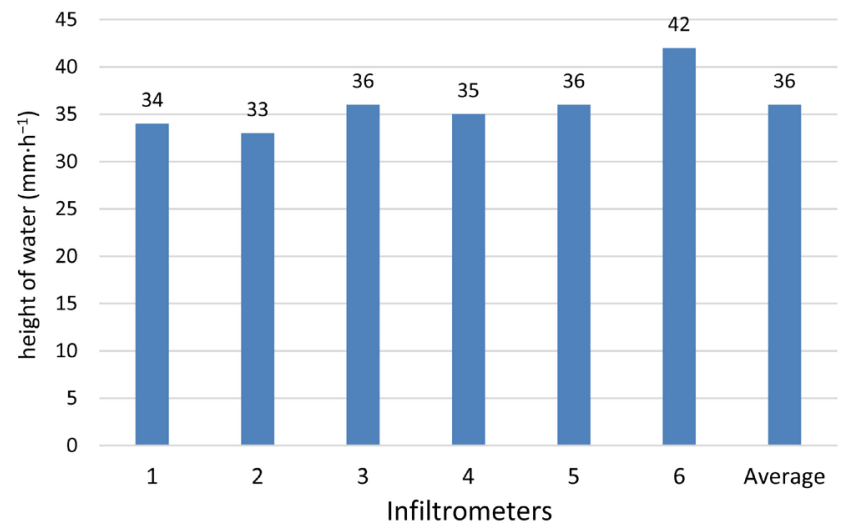

Figure 5. Basic rate of water infiltration into the soil mapping unit São Pedro (Argissolo read distófic arênic).

Table 1. Regression equations of number of pulses and the volume of water applied by eached infiltrometer.

\begin{tabular}{ccc}
\hline Infiltrometer & Regression equations & $\mathbf{R}^{2}$ \\
\hline 1 & $Y=0.0003 X+0.0326$ & 0.993 \\
2 & $Y=0.0001 X+0.039$ & 0.986 \\
3 & $Y=0.0001 X+0.0327$ & 0.961 \\
4 & $Y=0.0004 X+0.0332$ & 0.981 \\
5 & $Y=0.0003 X+0.0314$ & 0.971 \\
6 & $Y=0.0003 X+0.0328$ & 0.938 \\
\hline
\end{tabular}

$X$ being the number of pulses per minute and $Y$ the volume of water in Liters $\mathrm{min}^{-1}$. 
Table 2. Results of the determination of the infiltration rate of each infiltrometer to the soil mapping unit São Pedro (Argissolo read distófic arênic).

\begin{tabular}{cccccccc}
\hline Infiltrometers & $\mathrm{N}^{\circ} 1$ & $\mathrm{~N}^{\circ} 2$ & $\mathrm{~N}^{\circ} 3$ & $\mathrm{~N}^{\circ} 4$ & $\mathrm{~N}^{\circ} 5$ & $\mathrm{~N}^{\circ} 6$ & Average \\
\hline Number of pulses & 34 & 33 & 36 & 35 & 36 & 42 & 36 \\
Infiltration rate $\left(\mathrm{mm} \cdot \mathrm{h}^{-1}\right)$ & 62.92 & 61.14 & 64.06 & 64.31 & 60.66 & 63.45 & 62.76 \\
\hline
\end{tabular}

\section{Conclusions}

The performance of the sensors on arduino free electronic prototyping platform applied to the double Muntz rings in recording the number of pulses generated by the electromechanical flow determination system is considered efficient based on the uniformity of the values obtained up to the limit of 3 pulses per second. Values over this limit the equipment loss the precision.

The system can be used to determine with accuracy the rate of soil water infiltration up to $100 \mathrm{~mm} \cdot \mathrm{h}^{-1}$, which is considered extremely high, fully meeting the demand and need for different soils. From the values of the determination coefficients $\mathrm{R}^{2}$, it can be said that the models of the regression equations describe $93 \%$ to $99 \%$ of the real values, showing the accuracy of the equipment.

In the field determination, with only one operator, the system behaved stable, showing no problems with the water flow or hardware.

\section{Conflicts of Interest}

The authors declare no conflict of interest.

\section{References}

[1] Sotério, P.W., Pedrollo, M.C. and Andriotti, J.L. (2016) Map of Isoietas of Rio Grande do Sul. 2006. http://www.cprm.gov.br/publique/?tpl=home

[2] Denardin, J.E., Kochhann, R.A. and Righes, A.A. (2005) Vertical Mulching: Technical Management of Runoff in Tillage. Tillage Magazine, 14, 37-39.

[3] Bastos, P., Busso, M. and Miller, S. (2012) Short and Long-Term Impacts of Drought: Evidence from Brazilian Municipalities. Working Paper. http://pages.uoregon.edu/cameron/WEAI-AERE-2012/Miller_paper.pdf

[4] Cauduro, F.A. and Dorfman, R. (1986) Manual of Laboratory and Field Tests for Irrigation and Drainage. Porto Alegre, PRONI-IPH-UFRGS, 216 p.

[5] Souza, A.R., et al. (2011) The Arduino Board: A Low Cost Option for Physics Experiments Assisted by PC. Institute of Physics, Federal University of Rio de Janeiro, Rio de Janeiro, RJ, Brazil.

[6] Hudson, N. (1977) Soil Conservation. Cornell University Press, Ithaca, New York, $315 \mathrm{p}$.

[7] Fagundes, E.A.A., et al. (2012) Determination of Infiltration and Water Infiltration Speed by the Ring Infiltrometer Method in Cerrado Soil in the Municipality of Rondonópolis-MT. Biosphere Encyclopedia, Knowing Scientific Center, Goiânia, Vol. 8, 369-378. 